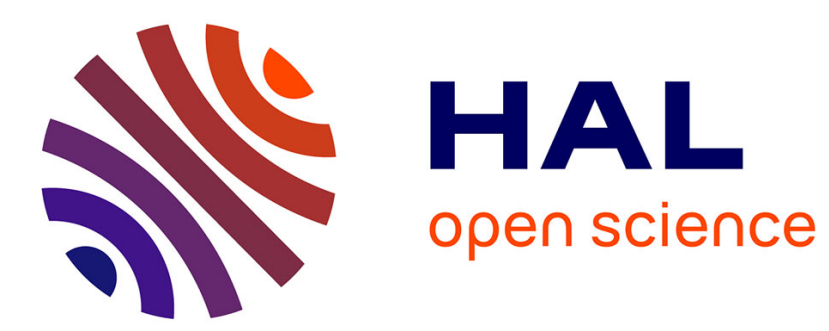

\title{
RAMAN STUDY OF GEOMETRICAL DISORDER AT SEMICONDUCTORS SURFACES
}

\author{
Robert Carles, J. Renucci, A. Zwick, M. Renucci
}

\section{To cite this version:}

Robert Carles, J. Renucci, A. Zwick, M. Renucci. RAMAN STUDY OF GEOMETRICAL DISORDER AT SEMICONDUCTORS SURFACES. Journal de Physique Colloques, 1982, 43 (C9), pp.C9363-C9-364. 10.1051/jphyscol:1982970 . jpa-00222499

\section{HAL Id: jpa-00222499 https://hal.science/jpa-00222499}

Submitted on 1 Jan 1982

HAL is a multi-disciplinary open access archive for the deposit and dissemination of scientific research documents, whether they are published or not. The documents may come from teaching and research institutions in France or abroad, or from public or private research centers.
L'archive ouverte pluridisciplinaire HAL, est destinée au dépôt et à la diffusion de documents scientifiques de niveau recherche, publiés ou non, émanant des établissements d'enseignement et de recherche français ou étrangers, des laboratoires publics ou privés. 


\title{
RAMAN STUDY OF GEOMETRICAL DISORDER AT SEMICONDUCTORS SURFACES
}

\author{
R. Carles, J.B. Renucci, A. Zwick et M.A. Renucci \\ Laboratoire de Physique des Solides Associé au CNRS,118, Route de Narbonne, \\ 31062 Touzouse Cedex, France
}

\begin{abstract}
Résumé.- Un désordre de nature géométrique est provoqué à la sunface d'échantilions par un pollisage mécanique grossier. Son influence sur les propriétés vibroniques et électroniques de InSb, InAs et GaSb est discutée.

Abstract.- Geometrical disorder is induced at the surface of samples by rough mechanical polishing. Its influence on both vibrational and electronic properties are reported in InSb, InAs and GaSb.
\end{abstract}

\begin{abstract}
1.- Introduction.- It is well known that optical properties of crystals (reflectivity, absorption, luminescence) depend strongly on surface preparation. It is prejudicial when studying bulk properties but provides, nevertheless, a mean of investigating damages at the surfaces. Among other optical techniques Raman spectroscopy is quite suitable to look at these damages since the penetration depth of the light can be small enough to study the disorder in the vicinity of the surface. Evans and Ushioda (1) were the first to realize this possibility. They took advantage of the broadening which characterizes the first onder Raman lines of polished surfaces to analyse the disonder induced by the polishing process. Recently, Carles et al (2) found that the Raman spectra of pure InAs samples alterated by mechanical polishing display two new bands labelled D.A.T.A. and D.A.L.A. which were interpreted as first order disonder activated processes. The study of these structures enables the characterization of this so-called "geometrical" disorder.
\end{abstract}

We present here results relativeto. InSb, InAs and GaSb. The influence of the geometrical disorder on the electronic properties of these compounds is also discussed.

2.- Experiment. - The samples analyzed were single crystals. which (100) surfaces were mechanically polished with $0.3 \mu$ alumina powder and then rinced in methanol. To avoid scattering from air the spectra were always recorded with the samples inside the vacuum chamber of the cryostat. They were not analyzed.

3.- Results and discussion.- We display in figures 1 and 2 respectively, the direct traces for InSb and InAs over a wide range of temperature. Arrows indicate phonons frequencies from ref. 3 and 4 . We present only the frequency range below the To( $\Gamma$ ) and LO $(\Gamma)$ which are still present in the spectra and well polarized (2).

In figure 1, besides the $2 \mathrm{TA}$ scattering characteristic of crystalline InSb two new. bands (D.A.T.A. and D.A.L.A.) appear confirming the results already found in InAs (2). At room temperature the D.A.L.A. is somewhat obscured by the end of the 2TA scattering (2IA(K) at $121 \mathrm{~cm}^{-1}$ ). As temperature decreases the second order scattering gets strongly attenuated (see the $2 \mathrm{TA}(\mathrm{X})$ for example) and the D.A.L.A. band merges around $137 \mathrm{~cm}-1$ at $25 \mathrm{~K}$. The apparent broadening of the low energy tail of the To( $\Gamma$ ), as temperature decreases, exemplifies the presence of disorder activated optical processes.

In figures 1 and 2 , the intensities of the D.A.T.A. and the D.A.L.A. become stronger, compared to that of the second order scattering, as one goes from $300 \mathrm{~K}$ to $25 \mathrm{~K}$. This 


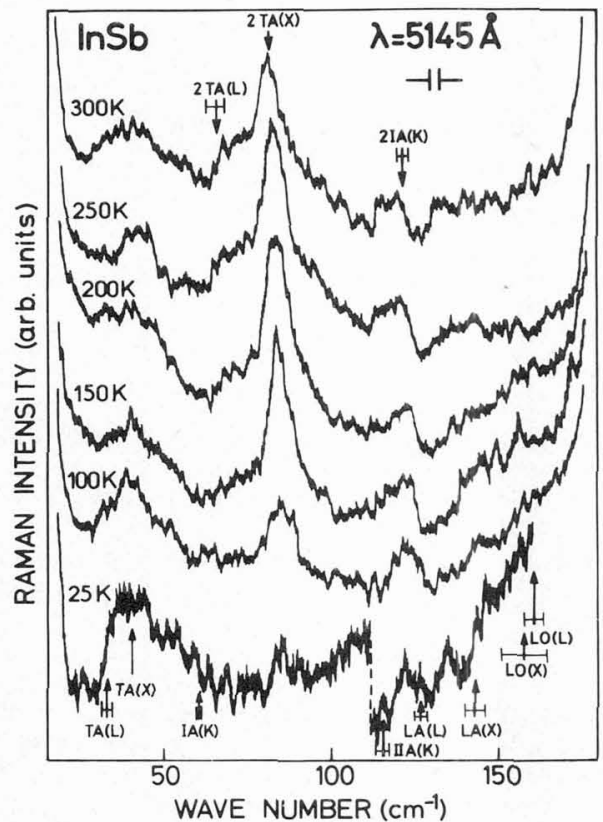

Figure 1.- Evolution with temperature Of the Raman spectrum of InSb alterated mechanically.

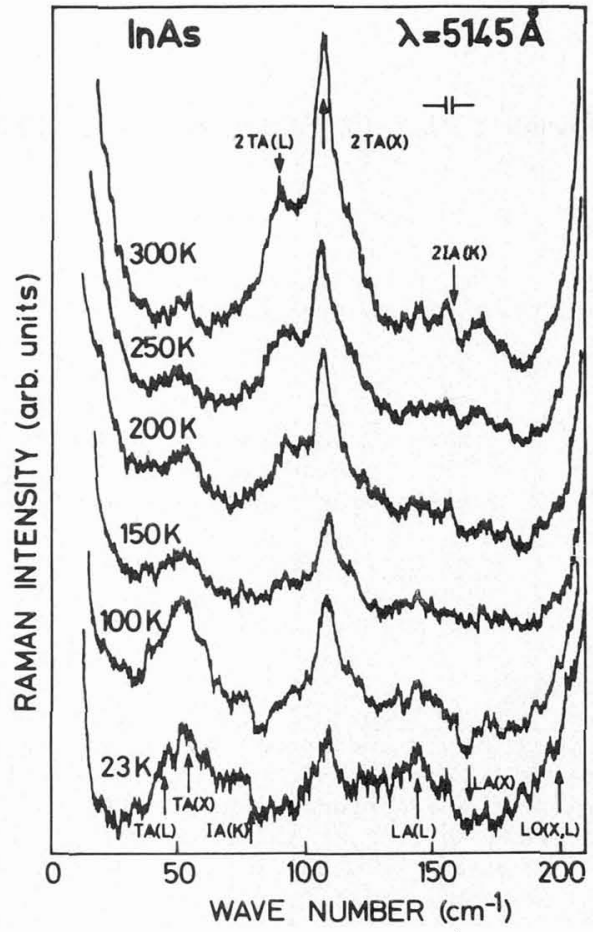

Figure 2.- Same as fig.1, for InAs.

behavion shows that they correspond to first order processes. In figure 2 , the intensity of the TO-TA band around $170 \mathrm{~cm}^{-1}$. follows the expected temperature dependance for a substractive combination.

The frequencies of the maxima of the D.A.T.A. and the D.A.L.A. are respectively half those of the $2 \mathrm{TA}(\mathrm{X})$ and $2 \mathrm{LA}(\mathrm{L})$ indicating that they correspond to transverse and longitudinal acoustical modes respectively. The D.A.T.A. and the D.A.L.A. appearing in both InSb and InAs near phonon frequencies characteristic of each compound rule out the eventuality of In-In modes. Also As-As or Sb-Sb modes would lie outside the frequency range explored (5).

At the lowest temperatures the shape of the D.A.T.A. mirrors that of the $2 \mathrm{TA}$ scattering : same kinds of singularities characteristic of $\mathrm{I}, \mathrm{X}$ and $\mathrm{K}$ points, same relative intensities of the bands at these points. The first assertion already proves that phonons of the whole Brillouin zone contribute to the D.A.T.A. in accordance with the breakdown of the $k=0$ selection rule. The second one, together with the fact that, in the III-V compounds, the 2TA scattering reflectsthe transverse accoustical one phonon density of states (3-4) with the scale doubled, implies that the D.A.T.A. too images this density of states.

From these facts, Carles et al. (2) proposed to fit, over the whole acoustical region, the disorder activated scattering in InAs by the expression :

$$
I_{1}=c_{1}(\omega) \quad g^{\prime}(\omega) \quad[\bar{n}(\omega, T)+1]
$$

$g^{\prime}(\omega)$ is the one phonon density of states of InAs convoluted by a gaussian to account for the broadening of the structures $; \bar{n}$ is the Bose Einstein factor ; $c_{1}(\omega)$ is the coupling constant of the light with the vibrational modes. The fit was excellent ta- 